\title{
Impact Evaluation of Leader Behaviour on Employee Commitment: Case Study of Plantation Sector in Sri Lanka
}

\author{
A.G.K. Wijesinghe
}

\begin{abstract}
Commitment of employees in the workplace is a key driver of its financial performance. Many researches have mentioned that the most powerful influence on employee commitment is the quality of leadership. Present study was conducted to find out the relationships between human-oriented leader behaviour and administrativelycompetent team-oriented leader behaviour in relation to employee commitment. Hence, this research mainly focused on two objectives to evaluate, (1) Whether "humanoriented leader behaviour" can enhance employee commitment (2) Whether "administratively-competent team-oriented leader behaviour" can enhance employee commitment. Two hundred and fifty employees were surveyed from six organizations in the plantation sector in Sri Lanka. Results revealed that humanoriented and administratively-competent team-oriented leader behaviours play important roles in determining the levels of employee commitment in the plantation sector organizations in Sri Lanka.
\end{abstract}

Keywords: Administratively-competent team-oriented leader behaviour, Employee commitment, Human-oriented leader behaviour

Department of Department of Agribusiness Management, Faculty of Agriculture and Plantation Management, Wayamba University of Sri Lanka, Gonawila 60170, Sri Lanka

Kusum_wijesinghe06@yahoo.com

\section{INTRODUCTION}

Many researches have pointed out that the most powerful influence on employee commitment is the quality of leadership. This is due to the managers in most of the corporations showing lack of listening, feedback, and delegation skills needed to enhance employee commitment in their organizations (Love, 2005). Creating employee commitment today is important more than ever before due to its positive contribution to organizational productivity, performance, employee satisfaction and lowering absenteeism (Payne and Huffman, 2005).

Profit margin of any company can be enhanced only by reduction of cost of production or service. Researches have mentioned effectiveness of the leadership is primary concern for profit to achieve the organizational goals and to create employee commitment (Suleman-Sabir et al., 2011). Studies on leadership and organizational commitment has mentioned transformational leadership is positively correlated with organizational commitment (Lo et al., 2010). Stites and Michael (2011) have also mentioned organizational commitment displays the attitude and the healthiness of the relationship between the employer and the employee. 
When workforce commitment is low then employees feel job insecurity, low trust, high stress and uncertainty in the organization, which lead to poor organizational performance (Panayiotis et al., 2011). Carlos and Filip (2011) have mentioned organization commitment can also increase the creativity in the organizations. Hesselbein and Cohen (1999), have emphasized the supervisor's job is not to command, but to persuade subordinates whenever necessary. It is critical for managers to influence their subordinates, peers, and superiors to motivate them to carry out their work effectively (Blickle, 2003).

International Survey Research (ISR) in the United States has shown that the level of commitment of the workers to their organization is a key factor of its financial performance. Further it has shown that organizations with high levels of employee commitment had reached to both operating margin and net profit margin (www.isrinsight.com). Sousa and Coelho, (2011) have mentioned organization commitment can have positive influence on the creativity in the organizations.

Leadership behaviour that encourage employee commitment is essential to develop business strategies, achieve their goals, gain competitive advantage and optimize human capital (Erasmus et al., 2003). The research conducted by Lo, Ramayah, Min and Songan (2010) mentioned that conflict between the leader and subordinate can be minimized when organizational culture is reflecting the employees' values.

\section{Theories of Leadership and Their Effectiveness in Organizations}

Past behavioural theories of leadership have mentioned, the behaviour of leadership affects employee commitment. Among these Ohio State and Michigan study, Hersey-Blanchard situational leadership theory (1977), Fiedler's theory (1967), House's Path-Goal theory (1971) and Blake Mouton's Managerial Grid (1982) are prominent. Burke (1985) has denoted "leadership has been a very controversial concept and it has more than 350 definitions". The majority of definitions of leadership reflect some common elements, such as "group", "influence" and "goal" (Bryman, 1992). Yukl (2010) defined leadership as the process of influencing others to recognize and agree about what needs to be done and how to do it.

Further, a research has mentioned considerate leaders are more effective in the work place as they are sociable, provide open communication, promote teamwork, and subordinates oriented (Daft, 2008). Siengthai and Bechter (2001) mentioned that leadership supports for innovation, organizational structure, human resource management, and organizational performance. Also, they have mentioned, not only good management and financial success, but also innovation appears to be with those leaders who had the creative ideas. 
According to the earliest research, the employee-oriented leaders appear to be associated with high group productivity and job satisfaction. Several researches have mentioned motivation, satisfaction, and work performance of followers depend on the leadership behaviour adapted by their administrators in the work place (Bycio et al., 1995; House, 1971; Sayles, 1981). Some other researchers have elaborated that a supportive leadership style creates a facilitating work environment of psychological support, mutual trust between each other's and respect, helpfulness, and friendliness that creates more productive work place (Hernandez et al., 2011). Therefore, effectiveness of leadership behaviours should be studied under own cultural values of a country.

\section{Employee Commitment}

Different researchers define commitment by focusing on different contexts. One of the earliest researchers in organizational commitment was Becker (1960), who regarded commitment as a continuous process for an individual towards the organization, and noted that individuals remain with the organizations because they acquire benefits (cited by Jahangir, 2003). Commitment is related to social involvement with colleagues and to increase length of organizational service. Also Lee (1971) defined commitment as the employees' feelings of belongingness or loyalty towards the organization. He found that commitment comes from employees' work accomplishment, relations with supervisors, and length of organizational service.

Meyer and Allen (1991) have identified an affective commitment refers to employee's emotional attachment, identification and involvement in the organization. Due to this loyalty feeling, employee feels to accept the company's goals and values as his/her own (Ashman and Winstanley, 2006). Continuance commitment is the employees' feeling of whether the costs of leaving an organization are greater than the costs of staying in the organization (Meyer and Allen, 1991). Normative commitment refers to the employees' feelings of obligation or responsibilities to stay within the organization they work (Jahangir, 2003).

Also, with an organizational culture that values and respects staff members had been most effective in producing higher level of organizational commitment (Sikorska-Simmons and Elizbieta, 2005). Organizational culture valued high adaptability and high-performance work practices has been found a significant and direct effect on employee commitment (Taylor et al., 2008). It is often assumed that commitment is built by "bottom-up" approach than "top-down" actions. Commitment can be influenced by creating sense of worth within employees in achieving an organizational goal. The responsibility of the leader is to create an environment open to each other and practice good relationship with employees to build trust within the system. Some 
authors argue that organizational commitment is influenced even by employees' knowledge of procedures and their perception of interpersonal procedural justice maintaining in the work place. Also, commitment can be achieved by encouraging a sense of belonging and satisfaction (Stephen and Annette, 1997). According to the literature, employee commitment is a feeling of dedication to one's employing organization, willingness to work hard for that employer (Meyer and Allen, 1991).

Therefore, it is worthwhile to know the attributes that can moderate employees' commitment in Sri Lankan organizations. Sri Lanka is behind in economic indicators when compared to developed nations in the world. One reason is low organizational productivity and low morale of the work force. Hence, this research will provide some insight into this area to understand the level of employee commitment in relation to identified leadership behaviours under its cultural reflection in Sri Lanka. Hence, current research is mainly focused on two objectives to study: (1) Whether "human-oriented leader behaviour" can enhance employee commitment in Sri Lankan Organizations (2). Whether "administratively competent team-oriented leader behaviour" can enhance employee commitment in Sri Lankan organizations. Based on that following theoretical framework and hypotheses were developed.

\section{Hypotheses}

1. Human-oriented leader behaviour can enhance employee commitment in the Sri Lankan Plantation Sector organizations.

2. Administratively-competent teamoriented leader behaviour can enhance employee commitment in the Sri Lankan Plantation Sector organizations. The experiments were conducted at the Department of Horticulture, Wayamba University of Sri Lanka, Makandura, from March to July 2014.

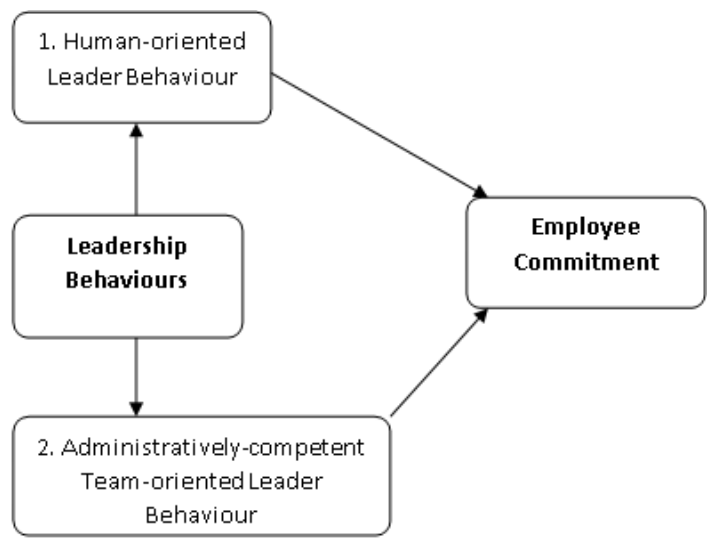

Figure 1. Conceptual frame-work

\section{MATERIALS AND METHODS}

The researcher adopted a questionnaire methodology for data collection. The reasons for using the questionnaire methodology were, keeping face confidentiality, to build up credibility and to save official time of participants for the survey. The study was conducted in the Plantation Sector Organizations in Sri Lanka. Respondents were middle managers, junior managers, and clerical staff. Two hundred and two complete questionnaires were subjected for data analysis. 
"Human-oriented leader behaviour" was measured by five items adapted by GLOBE project (House et al., 2004) and Li, 2006 study. The scale showed satisfactory reliability (Cronbach's alpha ranging from 0.73 to 0.82). "Administratively-competent Teamoriented leader behaviour" was measured by six items. Three items were adapted by GLOBE project (House et al., 2004) and Li, 2006 study. Three items were selfconstructed to measure employees' ratings on their leaders' administrative competencies. The scale showed satisfactory reliability (Cronbach's alpha ranging from 0.90-0.91).

Employee commitment was measured by four questions, adapted by Li, 2006 study. The scale showed satisfactory reliability (Cronbach's alpha ranging from 0.82-0.85). All items were measured by 7 point Likert scale ranging from $1=$ strongly disagree to $7=$ strongly agree. Four demographic variables were used as control variables: age, gender, job tenure to the current company and years of total work experience. Past research has suggested that these demographic attributes may moderate the effects of leadership in organizations (Chatman, 1991; Li, 2006). To test hypotheses, Analysis of Covariate (ANCOVA) in GLM procedure in SAS was performed. Pearson's correlation was adapted to measure correlations. Scatter diagrams and box-plots were performed to elaborate the distribution of the data.

\section{RESULTS AND DISCUSSION}

According to the results in the Table 1, mean value for human-oriented leader behaviour is 4.75 in this population while mean value for team-oriented leader behaviour is 5.57 . It shows that leaders in this study population is more team-oriented than human-oriented. According to the GLOBE project study in 62 countries (House et al., 2004) they have mentioned that the score for team-orientation of leaders was 5.86 in South Asian cluster. In this study it shows as 5.57 in the plantation sector of Sri Lanka. But this sample shows comparatively lesser value for humanorientation that is 4.75 in this population. GLOBE study has mentioned that it was as 5.38 in South Asian Cluster which was the highest from all other clusters (House et al., 2004).

According to the findings in the Table 1, administratively-competent teamoriented leader behaviour shows positive and significant correlation on employee commitment in these organizations in the plantation sector in Sri Lanka, $(r=0.753$, $\mathrm{p}<0.01$ in 2-tailed). Also human-oriented leader behaviour shows positive and significant correlation on employee commitment $(\mathrm{r}=0.573, \mathrm{p}<0.01$ in 2tailed). According to these results, administratively-competent team-oriented leader behaviour shows higher correlation to employee commitment than humanoriented leader behaviour in the study population. In the Table 2, analysis of covariate indicates that human-oriented leader behaviour and team-oriented leader 
Table 1. Descriptive statistics

\begin{tabular}{lllllllll}
\hline Factors & M & SD & $\mathbf{1}$ & $\mathbf{2}$ & $\mathbf{3}$ & $\mathbf{4}$ & $\mathbf{5}$ & $\mathbf{6}$ \\
\hline $\begin{array}{l}\text { Independent variable } \\
\text { Human-Leader }\end{array}$ & 4.75 & .82 & 1 & & & & & \\
$\begin{array}{l}\text { Ad.team-Leader } \\
\text { Dependent variable }\end{array}$ & 5.57 & 1.09 & $0.76^{* *}$ & 1 & & & & \\
Commitment & $\mathbf{5 . 2 5}$ & .94 & $0.57^{* *}$ & $0.75^{* *}$ & 1 & & & \\
Covariates & & & & & & & & \\
Sex & 1.4 & .38 & -0.05 & 0.005 & 0.01 & 1 & & \\
Age & 41 & 6.4 & -0.07 & $-0.15^{*}$ & $-.21^{* *}$ & -.06 & 1 & \\
Copany tenure & 10 & 4.3 & .039 & -.002 & -0.11 & -.03 & $.79^{* *}$ & 1 \\
Total experience & 13.1 & 5.6 & 0.008 & -0.04 & -0.10 & 0.002 & $0.73^{* *}$ & $.85^{* *}$ \\
\hline
\end{tabular}

** Correlation is significant at the 0.01 level (2-tailed); $\mathrm{N}=202$

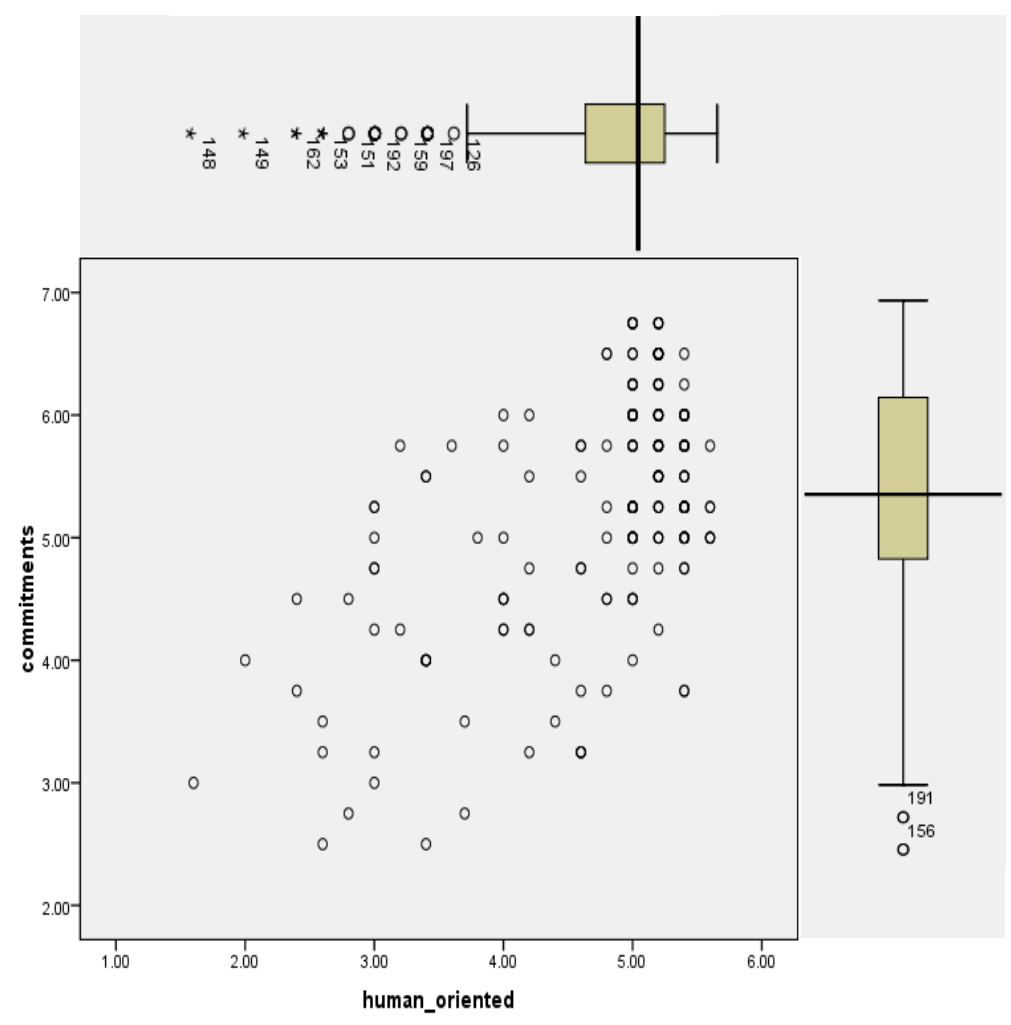

Figure 2. Distribution of data in employee commitment with human-oriented leader behavior 


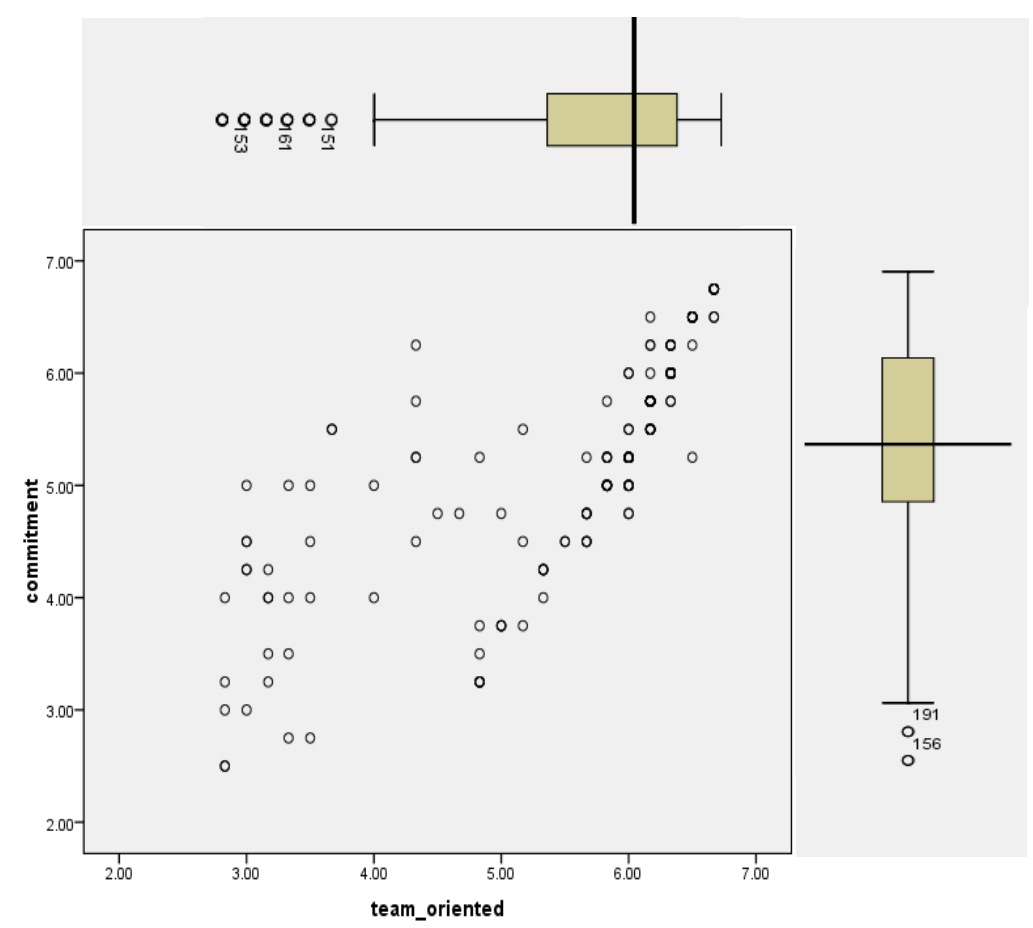

Figure 3. Distribution of data in employee commitment with administratively- competent team-oriented leader behaviour

Table 2. Analysis of covariates (ANCOVA) in relation to employee commitment under human-oriented and administratively-competent team-oriented leader behaviors

\begin{tabular}{lcc}
\hline \multicolumn{1}{c}{ Variable } & F value & P value \\
\hline Human-oriented leader (HL) & 53.58 & $0.0001^{* * *}$ \\
Ad-competent team-oriented leader (ATL) & 84.08 & $<.0001 * * *$ \\
\hline
\end{tabular}

$* \mathrm{p}<.05, * * \mathrm{p}<.01, * * * \mathrm{p}<.001 ; *$ Correlation is significant at the 0.05 level (2-tailed)

behaviour are significant in $1 \%$ probability on employee commitment.

Scatter diagrams and box-plots (Figure 2 and Figure 3) elaborate the distribution of data in this population in relation to the leadership behaviours and the employee commitment. Data of the human-oriented leader behavior were skewed to right (Figure 2). It means if leaders' human-orientation is more employees' commitment will be higher. 
Median has been laid above the mean of the data. Also, the data of the commitment were skewed to right. Median of the commitment has been laid above five. Both variables have lower outliers, lower fence and upper fence in the data distribution. Due to there are lower outliers in this population it shows that there are employees in this population who think as their leaders are very low human-oriented in their behaviors. But majority of the employees feel that their leaders are human-oriented.

Values of employee commitment under administratively-competent teamoriented leader behaviour were skewed to right (Figure 3). Also, there were lower outliers, lower fences and upper fence. Lower outliers show that there are employees in this population who think as their leaders are less administrativelycompetent team-oriented in their behaviors. But majority of the employees feel that their leaders are administrativelycompetent team-oriented.

\section{CONCLUSION}

According to these results, researcher can conclude that both human-oriented leader and administratively-competent teamoriented leader behaviours can enhance employee commitment in organizations in the plantation sector in Sri Lanka. These results provide evidence to prove hypotheses 1 and 2 in this study. It means, in order to enhance employee commitment to the organization, leader should adopt human-oriented behaviour in leading employees. And also, if leader adopts administratively-competent team-oriented behaviour in leading employees, employee commitment can be enhanced.

Based on these, the researcher can predict that leader behaviour is a good predictor for employee commitment in organizations. Further studies should be conducted in different sectors to learn about these leadership behaviours in relation to employee commitment. As well as it is essential to study about other leadership behaviours in relation to employee commitment in Sri Lankan organizations.

\section{REFERENCES}

Ashman, I. and Winstanley, D. (2006). The ethics of organizational commitment. Business Ethics: A European Review, 15(2): 142-153.

Blake, R. and Mouton, S.J. (1982). A Comparative analysis of situationalism and 9,9 management by principle, Organizational Dynamics, 10(4): 20-43.

Blickle, G. (2003). Convergence of agents' and targets' reports on intraorganizational influence attempts. European Journal of Psychological Assessment, 19(1): 40-53.

Bryman, A. (1992). Charisma and Leadership in Organizations, $1^{\text {st }}$ edition, London: Sage.

Burke, W. W. (1985). Leaders: The strategies for taking charge, by Warren Bennis and Burt Nanus. Human Resource Management, 24(4): 
503-508.

Bycio, P., Hackett, R. D. and Allen, J. S. (1995). Further assessments of Bass's conceptualization of transactional and transformational leadership. Journal of Applied Psychology, 80(4): 468478.

Carlos, M. P. and Filipe, C. (2011). From personal values to creativity: evidence from frontline service employees. European Journal of Marketing, 45(7/8): 1029-1050.

Chatman, J. (1991). "Matching people and organization: selection and socialization in public accounting firms". Administrative Science Quarterly, 36(4.): 459-84.

Daft, R. L. (2008). The Leadership Experience (4th ed.). Boston: SouthWestern College Pub.

Datta, D., Guthrie, J. P. and Wright, P.K. (2003). HRM and firm productivity: Does industry matter, Paper presented to the academy of management meetings, settle.

Stephen, S.P., and Annette, C. D. (1997). How Does Fair Treatment Affect Employee Commitment to an Organization? A Field Study of Financial Holding Company Employees. The Mid-Atlantic Journal of Business, 33 (3): 191-201.

Erasmus, B., Swanepoel, B. and Wyk, V. (2003). South African Human Resource Management: Theory \& Practice, $3^{\text {rd }}$ edition, UK, Juta \& Co.

Fiedler, F.E. (1967). A theory of leadership effectiveness, New York: Willy.

Hernandez, M., Eberly, M. B., Avolio, B. J. and Johnson, M. D. (2011). The loci and mechanisms of leadership: Exploring a more comprehensive view of leadership theory. The Leadership Quarterly, 22(6): 1165-1185.

Hersey, P. and Blanchard, K.H. (1977). Management of organizational behavior: Utilizing human resource. $3^{\text {rd }}$ edition, Englewood Cliffs, Prentice Hall, Inc.

Hesselbein, F. and Cohen, P. M. (1999). The shape of things to come. Leader to Leader: Enduring Insights on Leadership. Drucker Foundation's Journal San Francisco: 109-120.

House, R.J., Hanges, P.J., Javidan, M., Dorfan, P.W. and Gupta, V. (2004). Culture, Leadership and Organizations: The GLOBE study of 62 Societies, USA, SAGE Publication, 918.

House, R.J. (1971). Path-goal theory of leader effectiveness. Administrative Science Quarterly, 16: 321-339.

International Survey Research, United State. Available from: www.isrinsight.com/pdf/insight/US_L eader_or_Follower2.pdf. (Accessed 9 August 2015).

Jahangir, N. (2003). The relationship between managers' use of power and employees' work variables in national commercial bank in Bangladesh, $\mathrm{PhD}$ thesis. Australian Catholic University, Australia.

Lee, S.M. (1971). "An empirical analysis of organizational identification". Academy of Management Journal. 14: 213-26.

Li, J. (2006). The interactions between person-organization fit and leadership 
styles in Asian firms, an empirical testing. , International Journal of Human Resource Management: 17(10): 1689-1706,

Love, J. (2005). How to enhance employee commitment and improve productivity, ezine articles. Available from: http://ezinearticles.

Lo, M.C., Ramayah, T., Min, H. W. and Songan, P. (2010). The relationship between leadership styles and organizational commitment in Malaysia: role of leader-member exchange. Asia Pacific Business Review, 16(1-2): 79-103.

Meyer, J. P. and Allen, N. J. (1991). A three-component conceptualization of organizational commitment. Human Resource Management Review, 1(1): 61-89.

Panayiotis, S., Pepper, A. and Phillips, M. J. (2011). Transformational change in a time of crisis. Strategic HR Review, 10(5): 28-34.

Payne, S. C. and Huffman, A. H. (2005). A longitudinal examination of the influence of mentoring on organizational commitment and turnover. Academy of Management Journal, 48(1): 158-168.

Sayles, L. R. (1981). Leadership: What Effective Managers Really Do and How They Do it, $2^{\text {nd }}$ edition, US: McGraw-Hill I

Siengthai, S. and Bechter, C. (2001). Strategic human resource management and firm innovation, Research and practice in human resource management, 9(1): 35-57.

Sikorska-Simmons and Elzbieta, (2005).
Predictors of organizational commitment among staff in assisted living, Gerontologist, 45(2): 196.

Sousa, C. and Coelho, F. (2011). From personal values to creativity: evidence from frontline service employees. European Journal of Marketing, 45(7/8): 1029 - 1050.

Stites, J. P. and Michael, J. H. (2011). Organizational commitment in manufacturing employees: Relationships with corporate social performance. Business \& Society, 50(1): 50-70

Suleman-Sabir, M.S., Sohail, A. and AsifKhan, M. (2011). Impact of Leadership Style on Organization Commitment: In a Mediating Role of Employee Values, Journal of Economics and Behavioral Studies, 3(2): 145-152.

Taylor, S., Levy, O., Boyacgiller, N.A. and Beechler, S. (2008). Employee commitment in MNCs: Impact of organizational culture, HRM and top management orientations, The International Journal of Human Resource Management, 19(4): 501527.

Yukl, G. A. (2010). Leadership in Organizations, $7^{\text {th }}$ edition, New York: Prentice Hall. 